\title{
The classification of urban systems: a review from monocentric to polycentric
}

\author{
Youyang You \\ International Business School \\ Yunnan University of Finance and Economics \\ Kunming, China \\ 85621767@qq.com
}

\begin{abstract}
A city could be defined either monocentric or polycentric, in the passage; a systematic review of the urban systems is developed. After defined the elements of disappearance of monocentric system, four types of polycentric system is classified. In conclusion, a city could be locally important or regionally important or even global important in its relevant spatial scale. Thus, the spatial scale of urban systems is crucial of analyzing the structure of urban system, be it in the local, regional, or global scale.
\end{abstract}

\section{Keywords—urban systems; monocentric; polycentric}

\section{INTRODUCTION}

In order to answer the question of how can we recognize the city's position in terms of monocentric or polycentric, be it in the local, regional or global scale? The answer would be traced to the morphological and functional aspects of urban systems. The passage gives a specification of the urban system definitions, a classification of urban systems.

Nowadays, as urbanization became a trend in the world, a review of the urban system could better help not only the urban planners, but also the policy makers. From monocentric to polycentric, the development of cities could be traced.

\section{THE MONOCENTRIC URBAN SYSTEM}

The characteristics of monocentric urban system at the local scale for the intra-urban pattern:

Until the 1970s the research of internal structure of cities mainly focus on the monocentric models largely based on the American case studies [1]. The monocentric urban system deploys the physical arrangement of declining average density of development with increasing distance from the center, where employment and business are centralized in the core with the surrounding circular residential area. One of the most influential approaches of monocentric model will be traced back to the conception of "The Growth of City" proposed by Ernest Burgess. In this monocentric urban system, the spatial "core-periphery" means that employment structure oriented at manufacturing and material oriented service, the hierarchical type stays dominant. With its excessive centralization and exclusion of interaction with other centers, the monocentric model may be found at the local scale for the intra-urban pattern for the contemporary urban system study. The gradual disappearance of monocentric models is the evolution of social and demographic dispersion and the advent of high-speed transport and improved communication technology, which enables both people and economic activities to from the core move into the other nodes (suburbs, out of town locations or other cities) for all kinds of businesses.

It could be found that those specific elements from the research of for economic and societal changes between the core and the peripheries, finally leading to the disappearance of monocentric urban systems.

TABLE I. THE ElEMENTS FOR THE DisApPEARANCE OF MONOCENTRIC SYSTEMS

\begin{tabular}{|c|c|}
\hline $\begin{array}{l}\text { Elements for the disappearance of } \\
\text { monocentric urban systems }\end{array}$ & Sources \\
\hline $\begin{array}{l}\text { Social and demographic reasons: The } \\
\text { rapid decentralization of economic } \\
\text { activities leads to the dispersion of } \\
\text { population, the distribution of employment } \\
\text { and the tendency of economic activity to } \\
\text { cluster in several interacting centers. }\end{array}$ & Clark,1998 \\
\hline $\begin{array}{l}\text { Business services and knowledge } \\
\text { related activities (the replacement of } \\
\text { information and services with the goods as } \\
\text { the dominant urban economic activities) }\end{array}$ & $\begin{array}{l}\text { Kloosterman \& } \\
\text { Musterd, } 2001\end{array}$ \\
\hline $\begin{array}{l}\text { The changed structure of household. } \\
\text { (Two-workers household structure leads to } \\
\text { the consideration of choosing an optimal } \\
\text { residential location for two people. }\end{array}$ & $\begin{array}{l}\text { Kloosterman \& } \\
\text { Musterd, } 2001\end{array}$ \\
\hline The existence of cross commuting & $\begin{array}{l}\text { Davoudi, 2003; } \\
\text { Kloosterman \& } \\
\text { Musterd, 2001 } \\
\end{array}$ \\
\hline $\begin{array}{l}\text { The increased mobility due to new } \\
\text { transport technologies; }\end{array}$ & Davoudi, 2003 \\
\hline $\begin{array}{l}\text { The multiplicity of travel patterns } \\
\text { (Diverse trip purpose besides the } \\
\text { commuting (shopping, tourism, leisure) }\end{array}$ & $\begin{array}{l}\text { Kloosterman \& } \\
\text { Musterd, } 2001\end{array}$ \\
\hline $\begin{array}{l}\text { The fragmentation of } \\
\text { distribution of activities. }\end{array}$ & Clark, 1998 \\
\hline
\end{tabular}

Those items above all related to the structural and functional changes of monocentric urban system, which elicits the gradual appearance of polycentric urban systems extending their territory based on the configuration of monocentric urban system. 


\section{The Polycentric URBAN System}

As has been mentioned, different people have different conceptions on polycentricity. For example, in terms of policy measures, European Spatial Development Perspective (ESDP) used this conception for linking the seemly conflicting goals of greater cohesion and competitiveness in Europe [4]. In terms of urban systems, the concept of polycentricity will have its contextual meaning as to the different spatial scales. As the scale increases, the concept of polycentricity becomes gradually less analytical, and instead becomes the expression of a normative agenda. Van der Laan (1998) gave a definition of polycentricity as a network system where central position of urban centers is no longer determined by their position in relation to their immediate surroundings, but more and more by their position within a network of transactions [5]. Uses the conception of network cities to conceptualize the polycentric urban systems at the regional scale, and the global scale. In the following description, the polycentricity has its specific urban system names as to the relevant spatial scales.

The general concept of polycentricity has been put to a wide variety of different uses at different spatial scales. The frequent occurrence of polycentricity in literature points to a normative interpretation rather than a more analytical one [7]. It is indeed the case that, as presented in the ESDP [7], polycentricity is a stated objective, which has been accepted as a descriptive concept, even while the arguments as to its meaning continue. This may in part be attributed to the fact that, no precise, empirically testable definition of polycentricity has gained wide acceptance. Thus, in view of the 'fuzziness' that the concept of polycentricity appears to have, one can make the contextual cases that attempt to define polycentricity on a range of changing scales. In the following part, I aim at describing some typical polycentric terms for getting clear the intrinsic characteristics of urban systems.

\section{A. Edge cities (cities within cities), at the local scale for the intra urban pattern of polycentricity}

In this intra-urban pattern, the process of growth in the suburban and even the outmost reaches of large metropolitan areas is called the evolution of edge cities, which is typical for the urban structure of Los Angeles with multiple urban cores [3]. It could easily find that in the metropolitan city of American case, with an outward oriented growth and intensification of a single large urban and its suburbs, the edge cities appears at the nodes of transportation network systems [5].They are the consequence of the population dispersion and clustered services in the areas far from traditional downtowns. In this local scale system, the population growth of suburban countries is increasing much faster than the one of city center, but no more faster than the one of edges cities [4].

\section{B. Metropolitan area, at the local/intraregional scale for the inter-urban pattern of polycentricity}

Metropolitan area is typical of including one or multiple urban centers, as well as satellite cities and rural areas that are socioeconomically closely connected to the core of urban areas. The basic concept of metropolitan has been formed since its adoption in the United State's Bureau of the Census in 1950. The metropolitan needs to be traced back to the "city-region" or "conurbation [10]. It describes the geographical distribution of interlinked urban areas, which stresses the structurally physical continuous build area. From this sense, it can find that at the early stage the definition of conurbation mainly focused on the physical relationships between the city cores and the commuting hinterlands. However, the definition adopted in 1950 moves beyond this structural limitation, focus not only the commuting hinterland of the city but more importantly on the areas which are much functionally connected to the city.

\section{Polycentric Urban Region, at the regional scale/inter regional scale for inter-urban pattern of polycentricity}

In general, a polycentric urban region is characterized by separate and distinct cities or smaller settlements which interact with each other to a significant extent[8]. The typical examples are the Randstad region in the Netherlands and the Rhur region in Germany. A diversity of concepts is applied to define the polycentric urban regions. Examples include "City region" [9], "megalopolis" [4] "Network cities" [5], "polynucleated metropolitan regions" [8], "POLYNET" [6]. The constructive contributions for normative defining the conception of polycentric urban region could be traced to some scholars. Offer a list of characteristics, summarized here, that a polycentric urban configuration can be assumed to possess [4]:

Firstly, they consist of a number of historically distinct cities.

Secondly, they lack a clear leading city which dominates in political, economic, cultural and other aspects (although, inevitably, one of these cities has the largest number of inhabitants).

Thirdly, they tend to consist of a small number of larger cities that do not differ that much in terms of size or overall economic importance, together with a greater number of smaller cities.

Next, the cities making up these polycentric configurations are located in more or less close proximity (mainly within maximum commuting distance) and, thus, are concentrated in one specific part of a country.

Finally, these cities are not only spatially distinct, but also constitute independent administrative entities

It could be found above that the researchers give well-defined descriptive definition on the characteristics of physical structure polycentric urban region (PUR). Based on the conception provided by Kloosterman and Musterd [1], developed a similar conception for the PUR, yet emphasized above-average functional interaction between discrete similar sized settlements, which provided the normative definition on the characteristics of functional PUR [2]. The most precise definition to date of polycentricity within a polycentric urban system is that offered by [4], who have developed a formal definition of polycentricity based on the rank-size distribution of settlements in an urban system. This approach might therefore best be thought of as a means of gauging the relative extents of morphological polycentricity, taking no account of functional linkages between settlements. It can be clear that, when defining the PUR, two important terms: morphological 
and functional polycentricity are closely related to that. As mentioned in [7], however, the polycentricity has typically been situated within a regional context and has been conceptualized in largely morphological terms, although functional connections tend to be assumed.

\section{World cities, at the global scale for inter-urban pattern of polycentricity}

The world cities system is constituted by a vast network of locales that are tied together by a multitude of direct and indirect functional exchanges which put the conceptions of world cities and network cities into the front. With regard to the world cites, the most important contributions to the world research deem inter-city relations crucial in linking urban development to the restructuring of the world economy [6]. In this network, the world cities marked a shift of attention towards global functional flows resulting from the critical servicing of world-wide production rather than to its formal command through corporate headquarters of multinational enterprises. In short, world cities approach focused on the functional attraction of Advanced Producer Services (APS) firms (providing professional, financial and creative services for businesses) to major cities with their knowledge-rich environments and specialist markets [8], From this idea, the position of world cities are not fettered by their own physical connectivity but rather influenced by their functional interactions [7]. Mentioned that regarding the polycentricity at the global scale, cities such as Hong Kong, Frankfurt, London and New York, are highly connected in terms of financial transactions and can be said to form a network, although they are not spatially proximate. Furthermore, the theory of network cities cannot be neglected in the discussion of world cities [6]. mentions a network city evolves when two or more previously independent cities, potentially complementary in function, strive to cooperate and achieve significant scope economies aided by high-speed transport and communication infrastructures. In this context, "network cities" has become commonplace, in which the cities are not intrinsically dependent on its physical shape, instead for particular function such as financial transactions, a group of cities can be close in functional network terms, while being physically distant in morphological network terms. Thus ,It could say that for the polycentricity of world cities, the functional connectivity is weighted more than the morphological connectivity.

\section{CONCLUSION}

From the description above, there is a bunch of research on the descriptive definitions of urban systems at different scales. It can conclude that in the current society, a city could be locally important or regionally important or even global important in its relevant spatial scale. Thus, the spatial scale of urban systems is crucial of analyzing the structure of urban system, be it in the local, regional, or global scale. When defining a specific term of urban system, it should restrict the nodes (cities) in the same spatial scale for the horizontal comparison among them, not for the different scales of vertical comparison. Furthermore, it is not hard to summarize that no matter whether the urban system is monocentric or polycentric, some typically intrinsic physical figures and functions within those urban systems are always mentioned in their specific definitions.

\section{A FURTHER DISCUSSION AND PROPOSITION FOR CHINESE URBAN SYSTEM}

It is an important feature and tendency that the internal spatial development in post-industrial era is from monocentric to polycentric pattern. The evolution in China is appeared as one sole main monocentral, multiple sub centers and potential centers, or even non-central composed together system. From those mixed and complexed urban system in China nowadays, a conclusion could be draw as the urban function location is dynamic, there's no static urban central; urban central could be multiple, even the main central might also be more than one; the further urban center might not rely on the productions and population agglomeration, instead of that, knowledge agglomeration is more relied on. One thing could be defined as "Chinese unique", which is government got policy strength when configuring the urban spatial structure, which makes configuring effective.

Thurs, we got the proposition that in order to promote the healthy development of the polycentricity in a postindustrial era in China, urban regional functions should be defined and adjusted by the corresponding government sections, the opportunity of revolution and development should be caught. Only by doing this, can the functional complementary urban spatial structure be built; meanwhile, this structure is crucial in that the formation of industrial facilities is relied on it. Chinese government should pay the effort to promote the urban transformation constantly.

\section{ACKNOWLEDGEMENT}

This paper is sponsored by Yunnan science and Technology Department application of basic research project-Youth project No.2014FD024. Some of the data in this paper were from Dr. Yang Haoran in Utrecht University, Therefore, thanks for the information and helps from Dr. Yang Haoran.

\section{REFERENCE}

[1] D. Albalate, G. Bel, X. Fageda, "Competition and cooperation between high-speed rail and air transportation services in Europe.," Journal of Transport Geography, vol. 42, 2015, pp. 166-174.

[2] D. Albalate, X. Fageda, "High-technology employment and transportation: Evidence from the European regions," Regional Studies, 2015, pp. 1-15.

[3] A. Bell, K. Jones, "Explaining fixed effects: Random effects modeling of time-series cross-sectional and panel data. Political Science Research and Methods," 2015, pp.133-153.

[4] Civil Aviation Administration of China (CAAC). (2010-2015) Statistical data on civil aviation of China 2010, 2011,2012, 2013, 2014, 2015. Beijing, China: China Civil Aviation Publishing House.

[5] X. Fu, "Low cost carrier competition and route entry in an emerging but regulated aviation market - The case of China. Transportation Research Part A: Policy and Practice," 2015.

[6] S.L. Hsuan, W.C. Ching, Z. Joe, "Super-efficiency DEA in the presence of infeasibility," European Journal of Operational Research , 2011, pp. 141-147.

[7] M. Jeffrey, "Woodridge. Introductory Economics - A modern Approach," Third Edition. Beijing: China Renmin University Press, 2007. 
[8] L. Li, and B.P.Y. Loo, "Railway development and air patronage in China, 1993-2012: Implications for low-carbon transport. Journal of Regional Science," 2016, pp. 1-16.

[9] P.J. Taylor, M. Hoyler, and R. Verbruggen, "External Urban Relational Process: Introducing Central Flow Theory to Complement Central Place Theory."
[10] F. Rolf, and G. Shawna, "DEA, directional distance functions and positive, affine data transformation.” Omega, 2013, pp. 28-30.

[11] S. Hennemann, T. Wang, and I. Liefner, "Dynamics of center-periphery patterns in knowledge networks - the case of China's biotech science and technology system," Physics, 2011. 